\title{
Inhibitory effect of platinum (II) complex of curcumin on non-small cell lung cancer via the PI3K-AKT pathway
}

\author{
Yu Wang, Chen Li* \\ Molecular Testing Center, The First Affiliated Hospital of Jinzhou Medical University, JinZhou 121000, Liao Ning Province, \\ China
}

*For correspondence: Email: re1162@163.com; Tel: +86-13841629131

\begin{abstract}
Purpose: To study the effect of platinum (II) complex of curcumin (PCC) on non-small cell lung cancer (NSCLC) using human NSCLC cell line A549.

Methods: The anti-proliferative and apoptotic effects of PCC against NSCLC were investigated using 3(4,5-dimethylthiazol-2-yl)-2,5-diphenyltetrazolium bromide (MTT), Annexin V-FITC/propidium iodide double staining, quantitative real-time polymerase chain reaction (qRT-PCR), and western blot assays. Results: First, MTT assay and Annexin V-FITC/propidium iodide double staining results revealed that PCC possesses strong anti-cancer potency and high safety, when compared with cisplatin. Western blotting and GRT-PCR results showed that PCC inhibited the viability of NSCLC cells, decreased the expressions of PI3K, VEGF, AKT and BCl-2, and upregulated the expression of PTEN.

Conclusion: These results indicate that PCC promotes apoptosis in A549 cells via PTEN/PI3K/AKT signaling pathways.
\end{abstract}

Keywords: Platinum-curcumin complex, Non-small cell lung cancer, Apoptosis, PI3K-AKT

\begin{abstract}
This is an Open Access article that uses a funding model which does not charge readers or their institutions for access and distributed under the terms of the Creative Commons Attribution License (http://creativecommons.org/licenses/by/4.0) and the Budapest Open Access Initiative (http://www.budapestopenaccessinitiative.org/read), which permit unrestricted use, distribution, and reproduction in any medium, provided the original work is properly credited.
\end{abstract}

Tropical Journal of Pharmaceutical Research is indexed by Science Citation Index (SciSearch), Scopus, International Pharmaceutical Abstract, Chemical Abstracts, Embase, Index Copernicus, EBSCO, African Index Medicus, JournalSeek, Journal Citation Reports/Science Edition, Directory of Open Access Journals (DOAJ), African Journal Online, Bioline International, Open-J-Gate and Pharmacy Abstracts

\section{INTRODUCTION}

Most lung cancer incidents (about $85 \%$ ) are due to NSCLC, while squamous cell carcinoma, large cell carcinoma, and adenocarcinoma occur less frequently [1-3]. Currently, surgery, chemotherapy, radiation and immunotherapy are the main courses of treatment for these cancers [4]. Among these, chemotherapy is the most widely used, but its effect is frequently unsatisfactory because of problems such as limited effectiveness, severe toxicity and multidrug resistance [5].
Consequently, natural products have attracted increasing attention in cancer therapy [6]. Curcumin (Cur) is a natural polyphenol (Figure 1) which plays role in inducing tumor differentiation and apoptosis, inhibiting blood vessel formation, and regulating the expressions of tumor suppressor genes and oncogene proteins $[7,8]$. The expectation is that this is a new type of natural antitumor drug with high efficiency and low toxicity. However the use of Cur has limitations because of its weak anti-tumor effect, low bioavailability and poor water solubility [9]. The gold standard primary therapy for NSCLC patients involves the application of platinum- 
linked treatment $[10,11]$. However, the lack of selectivity between normal cells and cancer cells creates more side effects [12,13]. Therefore, in the present study, platinum (II) complex of curcumin was used (PCC, Figure 1) to investigate if the anti-cancer effects of curcumin could be improved, and also to see if the toxicity of cisplatin could be relieved. The specific mechanism of this complex was also investigated.
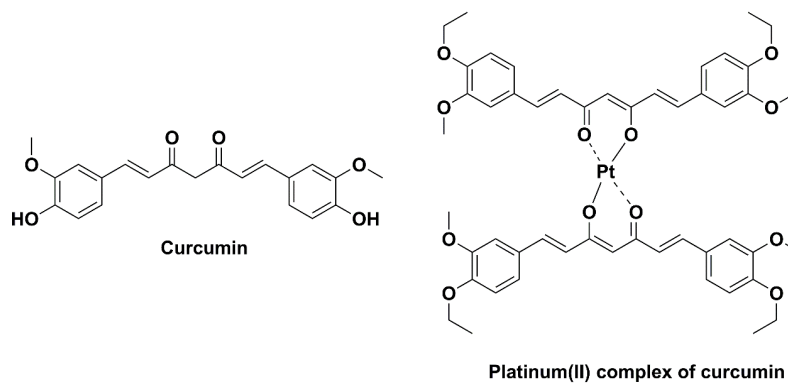

Figure 1: Structures of curcumin and platinum (II) complex of curcumin

\section{EXPERIMENTAL}

\section{Materials and reagents}

Professor Shuangsheng Zhou of the Anhui College of Traditional Chinese Medicine designed and provided the platinum (II) complex of curcumin. Curcumin and cisplatin (Cis) were products of Chengdu Herbpurify Co., LTD (Chengdu, China) and Sigma Chemical Co. (St. Louis, USA) respectively. They were dissolved in DMSO as stock solution. Sigma Chemical Co (St. Louis, USA) was the source of 3-(4,5dimethylthiazol-2-yl)-2,5-diphenyltetrazolium bromide (MTT).

\section{Cell lines and cell culture}

Human non-small cell lung cancer cell lines (A549 and SPC-A1), and normal lung cell line HBE were bought from KeyGEN BioTECH (Nanjing, China). These cell lines were cultured in Roswell Park Memorial Institute (RPMI)-1640 medium containing $10 \%$ heat-inactivated fetal bovine serum (FBS, Hyclone Laboratories) and 1 $\%$ penicillin-streptomycin antibiotic mixture (Gibco BRL) at $37{ }^{\circ} \mathrm{C}$ with $5 \% \mathrm{CO}_{2}$. The cells were used at the exponential growth phase.

\section{Cell viability assay}

Each cell culture was collected and transfected for $24 \mathrm{~h}$ before digestion with $0.25 \%$ trypsin. After re-suspending in complete medium, the cells were separately plated in $100-\mu \mathrm{L}$ culture medium in 96-well plates at density of $1 \times 10^{4}$ cells/well, and incubated with various concentrations of the different drugs for 48 hours. Four hours before the end of the incubation, MTT dye $(10 \mu \mathrm{L}$ of $2.5 \mathrm{mg} / \mathrm{mL}$ in PBS) was added to the wells, followed by further 4 hour-incubation at $37^{\circ} \mathrm{C}$ in the $5 \% \mathrm{CO}_{2}$ atmosphere.

Next, each plate was centrifuged for $15 \mathrm{~min}$ at 1500 rpm before discarding the supernatant without disturbing the well cells and the formazan crystals. The formazan crystals were solubilized in DMSO $(150 \mu \mathrm{L})$ before using a plate shaker to agitate the plates for $5 \mathrm{~min}$. A microplate reader (Thermo, USA) was employed to read the optical density (OD) at $490 \mathrm{~nm}$, and the $\mathrm{IC}_{50}$ values were calculated using GraphPad Prism 6.0. All assays were carried out in triplicate.

\section{Determination of cell apoptosis}

The A549 cells were seeded at $1 \times 10^{5}$ cells per well in a 6-well microtiter plate. After exposure to PCC $(0,10$, and $30 \mu \mathrm{M})$ for $24 \mathrm{~h}$, they were trypsinized before washing twice with chilled PBS and then re-suspending in a binding buffer. Next, each cell was subjected to Annexin V-FITC/PI double staining using apoptosis detection kit (Nanjing Jiancheng Bioengineering Institute) based on the manufacturers protocol. Flow cytometry (BD FACS Calibur, USA) was then used to analyse cellular fluorescence. Each experiment was carried out in triplicate.

\section{PCR analysis}

Total RNA was extracted from the cells treated with 0,10 , and $30 \mu \mathrm{M} \mathrm{PCC}$, and also from cells treated10 $\mu \mathrm{M}$ Cis in different groups. To determine the mRNA expressions of VEGF, PTEN and P13K, the extracted total RNA was reverse-transcribed to cDNA using kits from First strand cDNA Synthesis (TransGen Biotech) in line with the kit manual protocol. The qRT-PCR was done using Top Green qPCR SuperMix (TransGen Biotech) coupled to a 96-well Piko Thermal Cycler system, with $\beta$-actin mRNA as internal control. Quantifications of mRNA expressions were carried out with comparative $\mathrm{Ct}$ procedure.

\section{Western blot}

Total protein was extracted from each cell line by grinding in RIPA buffer containing $1 \mathrm{mM}$ PMSF (Cell-Signalling Tech., US). The protein levels were quantified with BCA protein assay kit (Thermo Fisher Scientific, MA, USA) according to the kit protocol. Primary antibodies for PTEN, $\mathrm{PI} 3 \mathrm{~K}$ and $\beta$-actin were bought from Cell Signalling Technology (Beverly, MA, USA), while 
the primary antibodies for VEGF, AKT, Bcl-2 were obtained from Abcam (Cambridge, UK). The internal reference used was $\beta$-actin. Chemiluminescence was measured with an $\mathrm{ECL}$ kit (Pierce Biotechnology) and a Bio-Rad molecular imager was used to visualise and capture the images of the resultant immunoreactive protein bands. The intensity of each band was calculated with ImageJ, and the results were normalised to that of $\beta$-actin.

\section{Statistical analysis}

Data are presented as mean \pm standard deviation (SD). Statistical analysis was done with one-way analysis of variance (ANOVA), followed by Tukey's multiple comparison. All analysis was done with GraphPad Prism 6. Statistical significance was set at $p<0.05$.

\section{RESULTS}

\section{In vitro cytotoxicity of PCC}

The $\mathrm{IC}_{50}$ values depicted in Figure 2 reveal that the inhibitory effects of PCC on lung adenocarcinoma cells was comparable to that of the positive control Cis, but superior to that of Cur. Aside from that, in normal HBE cells, PCC

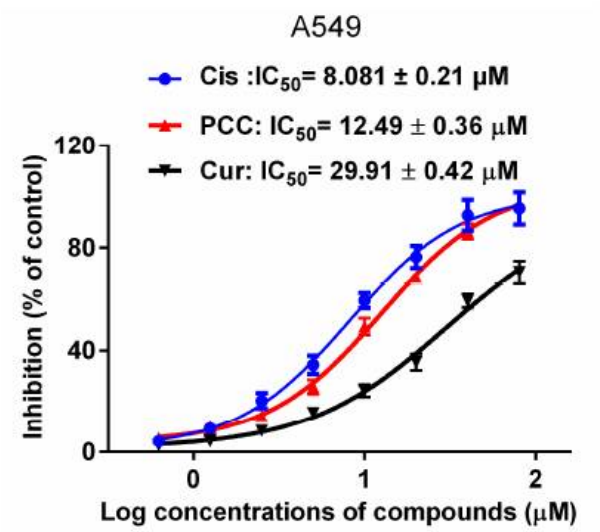

almost exhibited no toxic effects, while Cis showed obvious inhibitory effect on the growth of HBE cells, with $\mathrm{IC}_{50}$ of $41.18 \mu \mathrm{M}$. This suggests that the complex sustained the relative safety of Cur and the potent activity of Cis.

\section{Results of flow cytometry for apoptosis}

Results from cytometry demonstrated that the pro-apoptotic effect of PCC on A549 cells was dose-dependent. Apoptosis in the low-dose PCC group $(45.3 \pm 2.8 \%)$ and the high-dose PCC group $(72.6 \pm 3.5 \%)$ were significantly higher than that in the normal control group $(p<0.001)$, indicating that the pro-apoptotic effect of PCC was comparable to that of Cis.

\section{Effect of PCC on the expressions of P13K, VEGF, and PI3K mRNAs}

As shown in Figure 4, data obtained from qRTPCR revealed that the expression of PTEN mRNA was significantly upregulated in the PCC and Cis groups, when compared to the normal control group, while the expressions of VEGF and PI3K mRNAs in the drug-treated groups were significantly lower $(p<0.05)$.

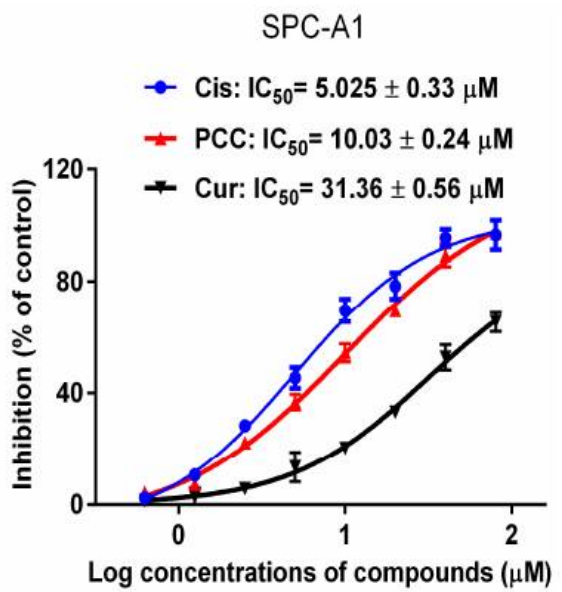

HBE

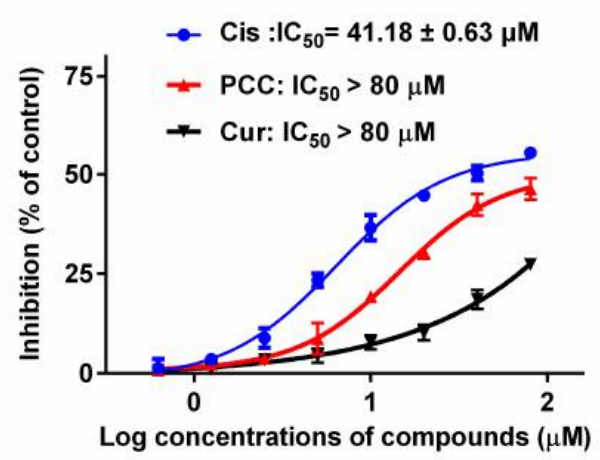

Figure 2: $I C_{50}$ for the potency of PCC on A549, SPC-A1 and HBE cell lines, as determined using MTT assay. Data are presented as mean $\pm S D(n=3)$ 


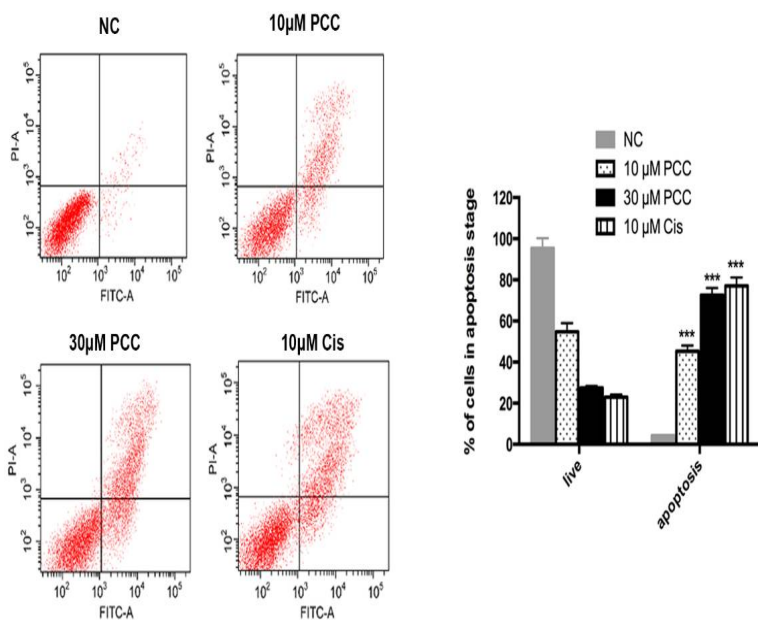

Figure 3: Pro-apoptotic effects of PCC on A549 cells, as determined with Annexin V-FITC/PI staining and flow cytometry. Data are presented as mean $\pm S D(n=$ 3)
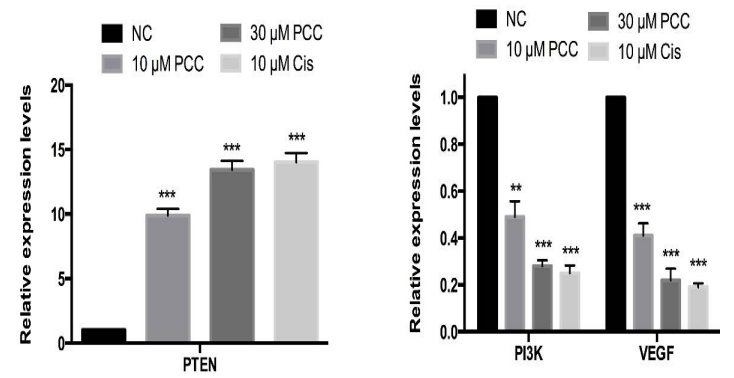

Figure 4: Effect of PCC on mRNA expressions of PTEN, PI3K and VEGF in A549 cells; ${ }^{*} p<0.05$, compared with the control group

\section{Effect of PCC on the expressions of VEGF and $A K T / P I 3 K$ pathway-related proteins in A549 cells}

Western blotting assay results revealed that in the drug-treated groups, PTEN expression was significantly increased while the PI3K, AKT, VEGF, and Bcl-2 expressions were depressed, relative to corresponding expressions in the normal control group (Figure 5). These results suggest that PCC exerts anti-lung cancer effect via regulation of the PTEN/PI3K/AKT signaling pathway.

\section{DISCUSSION}

Although anti-cancer therapies such as radiotherapy, chemotherapy, and targeted therapies have witnessed some advances, the five years survival remains low (< $15 \%)$ [14]. Curcumin occupies a vital position as a paramount source of anti-cancer drugs, but its use is limited because of a weak anti-tumor effect, low bioavailability and poor water solubility [15]. The gold standard therapy for NSCLC is platinum-based chemotherapy, which also has severe side effects [16]. In the present study, the anticancer effect of a combination of the two drugs was studied. First, the cytotoxicity of PCC on human NSCLC cell lines A549 and SPC-A1, as well as normal human bronchial epithelial cell line HBE was determined. Conclusions were easily drawn that PCC had potent ability to inhibit NSCLC cancer cell growth at a level comparable to that of cisplatin, and superior to that of curcumin. In addition, it had no effect on normal cells, indicating it was safer than cisplatin. Double staining with Annexin V-FITC/PI produced consistent results, showing the ability of PCC to induce significant cell apoptosis in a dose-dependent manner.

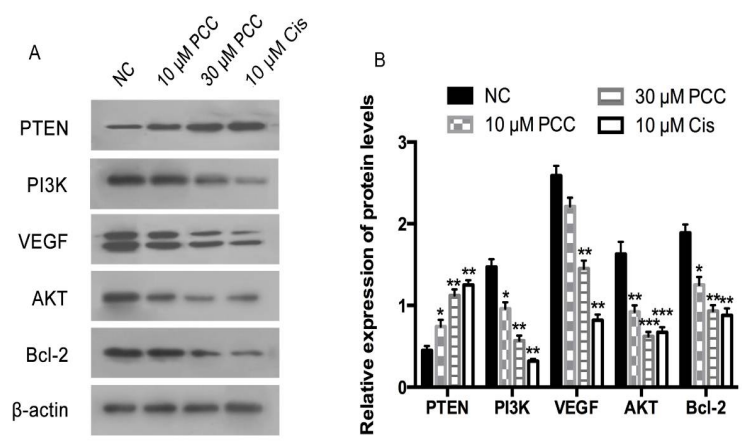

Figure 5: Effect of PCC on expressions of PTEN/PI3K/AKT signaling pathway-associated proteins. Data are expressed as mean $\pm \mathrm{SD}(\mathrm{n}=3) ;{ }^{*} p$ $<0.05,{ }^{* *} p<0.01,{ }^{\star * *} p<0.001$, compared with the normal control group

Researchers have found multiple signaling pathways which are linked to lung cancer. These include the PI3K-AKT [17 - 19], VEGF [20-22], and P53 [23-25] signaling pathways. There is agreement with the fact that PTEN is a dual protein/lipid phosphatase. The central substrate is a product of $\mathrm{P} 13 \mathrm{~K}$, i.e. phosphatidylinositol 3,4,5 triphosphate (PIP3) [26]. Cyclins and Bcl-2 proteins correlate closely with cell cycles and apoptosis, respectively [27].

It is known that VEGF mediates the migration and proliferation of endothelial cells, as well as angiogenesis and survival [28-30]. Thus, in order to determine the effect of PCC on the related proteins, the relative expression levels of VEGF, $\mathrm{PI} 3 \mathrm{~K}$ and PTEN; and the relative protein expression levels of VEGF, PI3K, PTEN, AKT and $\mathrm{Bcl}-2$ were determined using $\mathrm{QPCR}$ and western blot, respectively. The results showed that PCC downregulated VEGF and PI3K mRNAs, but upregulated PTEN mRNA. The changes in protein expressions were in agreement with the pattern of expressions of mRNAs. 


\section{CONCLUSION}

These results suggest that treatment of PCC prevents A549 cell proliferation via regulation of the PISK/AKT signaling pathway (34-35). PCC exerts anticancer effect on NSCLC, most likely via regulation of PTEN side of PI3K/AKT signaling pathway rather than through $\mathrm{PI} 3 \mathrm{~K}$ axis. Therefore, PCC is a potential novel anti-lung cancer drug candidate.

\section{DECLARATIONS}

\section{Conflict of Interest}

No conflict of interest associated with this work.

\section{Contribution of Authors}

This work was done by the authors named in this article and the authors accept all liability resulting from claims which relate to this article and its contents. The study was conceived and designed by Xingxiang $\mathrm{Xu}$; Junjun Yang, Lingfeng Min, Zhenghua Jiang, Wenjing $X u$ and Hanqing Yao collected and analysed the data, while Yanming Geng and Jiarong Bian wrote the manuscript. All authors read and approved the manuscript prior to publication.

\section{REFERENCES}

1. Ferlay J, Soerjomataram I, Dikshit R, Eser S, Mathers C, Rebelo M, Parkin DM, Forman D, Bray F. Cancer incidence and mortality worldwide: sources, methods and major patterns in GLOBOCAN 2012. Int $J$ Cancer 2015; 136: 359-386.

2. Pikor LA, Ramnarine VR, Lam S, Lam WL. Genetic alterations defining NSCLC subtypes and their therapeutic implications. Lung Cancer 2013; 82: 179189.

3. Lindsay CR, Shaw E, Popat S, Blyth KG, Walker I, Chaturvedi A, Dick C, Rass/ D, Taniere $P$, Johnson PWM, et al. 13 - KRAS Subtypes in non-small cell lung cancer (NSCLC) within Phase I of the Cancer Research UK Stratified Medicine Programme (SMP1). Lung Cancer 2018; 115.

4. Alongi F, Arcangeli S, Ramella S, Giaj-Levra N, Borghetti $P$, D'angelillo R, Ricchetti F, Maddalo M, Mazzola R, Trovò $M$, et al. From chemotherapy to target therapies associated with radiation in the treatment of NSCLC: a durable marriage? Expert Rev Anticancer Ther 2017; 17: 157.

5. Cascella M. Chemotherapy-induced peripheral neuropathy: limitations in current prophylactic strategies and directions for future research. Curr Med Res Opin 2017: 1-7.
6. Greenlee H. Natural products for cancer prevention. Semin Oncol Nurs 2016; 32: 215.

7. Nelson KM, Dahlin JL, Bisson J, Graham J, Pauli GF, Walters MA. The Essential Medicinal Chemistry of Curcumin. J Med Chem 2017; 60: 1620-1637.

8. Xu $X$, Zhu $Y$. Curcumin inhibits human non-small cell lung cancer xenografts by targeting STAT3 pathway. Am J Trans/ Res 2017; 9: 3633.

9. Maria $D N$, Mishra SR, Wang L, Abd-Elgawad AH, Soliman OA, El-Dahan MS, Jablonski MM. Watersoluble Complex Of Curcumin With Cyclodextrins: Enhanced Physical Properties For Ocular Drug Delivery. Curr Drug Deliv 2016; 13: 1-1.

10. Yin JY, Li X, Zhou HH, Liu ZQ. Pharmacogenomics of platinum-based chemotherapy sensitivity in NSCLC: toward precision medicine. Pharmacogenomics 2016; 00: 1365-1378.

11. Rossi A, Di MM. Platinum-based chemotherapy in advanced non-small-cell lung cancer: optimal number of treatment cycles. Expert Rev Anticancer Ther 2016.

12. Oun R, Moussa YE, Wheate NJ. The side effects of platinum-based chemotherapy drugs: a review for chemists. Dalton Trans 2018.

13. Rajeswaran A, Trojan A, Burnand B, Giannelli M. Efficacy and side effects of cisplatin- and carboplatin-based doublet chemotherapeutic regimens versus nonplatinum-based doublet chemotherapeutic regimens as first line treatment of metastatic non-small cell lung carcinoma: a systematic review of randomiz. Lung Cancer 2008; 59: 1-11.

14. Leon G, Macdonagh L, Finn SP, Cuffe S, Barr MP. Cancer stem cells in drug resistant lung cancer: Targeting cell surface markers and signaling pathways z. Pharmacol Ther 2016; 158: 71-90.

15. Ji JL, Huang XF, Zhu HL. Curcumin and its formulations: potential anti-cancer agents. Anticancer Agents Med Chem 2012;12: 210-218.

16. Kosmidis P. Chemotherapy in NSCLC: historical review. Lung Cancer 2002; 38: 19-22.

17. Liu Y, Ma T. Metabolic regulation of mesenchymal stem cell in expansion and therapeutic application. Biotechnol Prog 2015; 31: 468-481.

18. Venkannagari S, Fiskus $W$, Peth $K$, Atadja $P$, Hidalgo $M$, Maitra A, Bhalla KN. Superior efficacy of co-treatment with dual PI3K/mTOR inhibitor NVP-BEZ235 and panhistone deacetylase inhibitor against human pancreatic cancer. Oncotarget 2012; 3: 1416.

19. Zhu H, Jiang $X X$, Guo ZK, Li H, Su YF, Yao YH, Wang $X Y, L i X S, W u Y$, Liu YL, et al. Tumor necrosis factoralpha alters the modulatory effects of mesenchymal stem cells on osteoclast formation and function. Stem Cells Dev 2009; 18: 1473.

20. Peng N, Gao S, Guo X, Wang G, Cheng C, Li M, Liu K. Silencing of VEGF inhibits human osteosarcoma angiogenesis and promotes cell apoptosis via VEGF/PI3K/AKT signaling pathway. Am J Trans/ Res 2016; 8: 1005-1015. 
21. Zhiping HE, Chen AY, Rojanasakul Y, Rankin GO, CHEN YI. Gallic acid, a phenolic compound, exerts antiangiogenic effects via the PTEN/AKT/HIF-1a/NEGF signaling pathway in ovarian cancer cells. Oncol Rep 2016; 35: 291-297.

22. Chen $H$, Cong $Q$, Du Z, Liao W, Zhang L, Yao Y, Ding $K$. Sulfated fucoidan FP08S2 inhibits lung cancer cell growth in vivo by disrupting angiogenesis via targeting VEGFR2/VEGF and blocking VEGFR2/Erk/VEGF signaling. Cancer Lett 2016; 382: 44-52.

23. Tao Z, Chen S, Mao G, Xia H, Huang H, Ma $H$. The $P D R G 1$ is an oncogene in lung cancer cells, promoting radioresistance via the ATM-P53 signaling pathway. Biomed Pharmacother 2016; 83: 1471-1477.

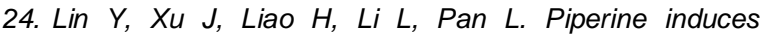
apoptosis of lung cancer A549 cells via p53-dependent mitochondrial signaling pathway. Tumour Biol 2014; 35 . 3305-3310.

25. Vaughan $C A$, Singh $S$, Grossman $S R$, Windle $B$, Deb $S P$, Deb $S$. Gain-of-function p53 activates multiple signaling pathways to induce oncogenicity in lung cancer cells. Mol Oncol 2017; 11.

26. Buckles TC, Ziemba BP, Masson GR, Williams RL, Falke JJ. Single-Molecule Study Reveals How Receptor and
Ras Synergistically Activate PI3Ka and PIP3 Signaling. Biophys J 2017; 113: 2396-2405.

27. Harvey KJ, Blomquist JF, Ucker DS. Commitment and effector phases of the physiological cell death pathway elucidated with respect to Bcl-2 caspase, and cyclindependent kinase activities. Mol Cell Biol 1998; 18: 2912-2922.

28. Moffat BA, Chen M, Kariaapper MST, Hamstra DA, Hall $D E$, Stojanovska J, Johnson TD, Blaivas M, Chenevert $T L$, et al. Inhibition of vascular endothelial growth factor (VEGF)-A causes a paradoxical increase in tumor blood flow and up-regulation of VEGF-D. Clin Cancer Res 2006; 12: 1525-1532.

29. Fan J, Bao Y, Meng X, Wang S, Li T, Chang X, Yang G, Bo T. Mechanism of modulation through PI3K-AKT pathway about Nepeta cataria L.'s extract in non-small cell lung cancer. Oncotarget 2017; 8(19): 31395-31405.

30. Qiu Q, Liu B, Cui J, Li Z, Deng X, Qiang H, Li J, Liao C, Zhang $B$, Shi $W$, et al. Design, Synthesis, and Pharmacological Characterization of $\mathrm{N}-\left(4-\mathrm{C}_{2} \quad(6,7-\right.$ Dimethoxy-3,4-dihydroisoquinolin-

2(1H)yl)ethyl)phenyl)quinazolin-4-amine Derivatives: Novel Inhibitors Reversing P-Glycoprotein-Mediated Multidrug Resistance. J Med Chem 2017; 60(8): 32893302. 